\title{
Prevalence and determinants of antepartum depressive and anxiety symptoms in expectant mothers and fathers: results from a perinatal psychiatric morbidity cohort study in the east and west coasts of Malaysia
}

Hashima E. Nasreen ${ }^{1 *}$ D, Jamalludin Ab Rahman ${ }^{1+}$, Razman Mohd Rus ${ }^{1+}$, Mira Kartiwi ${ }^{2+}$, Rosnah Sutan ${ }^{3+}$ and Maigun Edhborg ${ }^{4 \dagger}$

\begin{abstract}
Background: Research on antepartum psychiatric morbidities investigating depressive and anxiety symptoms in expectant mothers and fathers is lacking in low- and middle-income countries. This study aimed to estimate the prevalence of antepartum depressive, anxiety and co-occurring significant symptoms and explore the associated factors in a cross-section of Malaysian expectant mothers and fathers.
\end{abstract}

Methods: We used cross-sectional data from a prospective cohort study of 911 expectant mothers and 587 expectant fathers during their third trimester of pregnancy, from health clinics of two states in the east and west coasts of Malaysia. The validated Malay version of Edinburgh Postnatal Depression Scale and the anxiety sub-scale of Depression, Anxiety and Stress Scale were used to measure the depressive and anxiety symptoms. Multiple logistic regression analyses identified the determinants of antepartum depressive and anxiety symptoms (ADS and AAS).

Results: Prevalence of ADS was $12.2 \%$ in expectant mothers and $8.4 \%$ in expectant fathers, while AAS was $28.8 \%$ in expectant mothers and $13.3 \%$ in expectant fathers, and co-occurring significant symptoms was $8.0 \%$ in expectant mothers and $4.0 \%$ in expectant fathers. Expectant mothers and fathers having perceived social/family support were less likely to suffer from ADS. Intimate partner violence, poor relationship with husbands, depression in earlier pregnancy and husband's depression in current pregnancy in expectant mothers, and living in rented house, sex preference for the unborn child, stressful life events and wife's depression in current pregnancy in expectant fathers were associated with a greater likelihood of ADS. The determinants for AAS were living in rented house and with parents/in-laws, poor relationship with husbands, restrictions during pregnancy and stressful life events for expectant mothers, and stressful life events and being unsupportive towards wives in household chores for expectant fathers.

(Continued on next page)

\footnotetext{
* Correspondence: drnasreen@iium.edu.my

${ }^{\dagger}$ Jamalludin Ab Rahman, Razman Mohd Rus, Mira Kartiwi, Rosnah Sutan and

Maigun Edhborg contributed equally to this work.

${ }^{1}$ Faculty of Medicine, International Islamic University Malaysia, Jalan Sultan

Ahmad Shah, 25200 Kuantan, Pahang, Malaysia

Full list of author information is available at the end of the article
}

(c) The Author(s). 2018 Open Access This article is distributed under the terms of the Creative Commons Attribution 4.0 International License (http://creativecommons.org/licenses/by/4.0/), which permits unrestricted use, distribution, and reproduction in any medium, provided you give appropriate credit to the original author(s) and the source, provide a link to the Creative Commons license, and indicate if changes were made. The Creative Commons Public Domain Dedication waiver (http://creativecommons.org/publicdomain/zero/1.0/) applies to the data made available in this article, unless otherwise stated. 
(Continued from previous page)

Conclusion: Both ADS and AAS are prevalent in expectant mothers and fathers, and largely an undetected problem in Malaysia. Administration of couple-based screening and referral program during antenatal check-up should be universal practices to identify and treat the psychiatric morbidities.

Keywords: Antepartum, Depressive symptoms, Anxiety symptoms, Associated factors, Expectant mothers and fathers, Malaysia

\section{Background}

High maternal perinatal depressive and anxiety symptoms are traditionally evident [1]. It is widely believed that only mothers are affected by depression during pregnancy and postpartum period. Therefore, most research are focused on mothers. However, contemporary research findings, mostly from high-income countries, suggest that fathers are also affected by depression during ante and postpartum period [2]. Recent research findings in high-income countries show that anxiety is more prevalent than depression among mothers during their perinatal period [1,3]. Moreover, anxiety and depressive symptoms are more prevalent during pregnancy than postpartum period both in mothers $[1,4]$ and fathers $[1,5]$. Meta-analysis indicates the mean weighted prevalence for maternal antepartum depressive symptoms (ADS) is $12 \%$ in high income countries [6] and about $20 \%$ in Asia [7]. The meta-estimation of paternal ADS was $8 \%$ with significant heterogeneity observed among prevalence rates ranging from 2 to $19 \%[2,4]$. Emerging literature reported that $18-25 \%$ of expectant mothers [1, 3] and 8-20\% of expectant fathers showed antepartum anxiety symptoms (AAS) [1]. Comorbid depressive and anxiety symptoms in mothers are common during pregnancy $[1,8]$, however, very few data are available about expectant fathers [1].

The prevalence of ADS and AAS tends to be higher in low- and middle-income countries (LMIC) than in high-income countries $[9,10]$. Although the World Health Organization (WHO) ranks depression as the leading cause of disease burden for women of childbearing age (15-44 years) [11], often both ADS and AAS go unrecognized and untreated in LMIC [12]. However, ADS has impact on infants, such as low birth weight [13], premature delivery [14], poor nutrition [15], difficult temperament, impaired cognitive development and conduct disorder during childhood [16], and more direct impact on mothers, such as impaired mother-infant relationship [17], poor partner relationship [12], alcohol and substance use [18], the postpartum depression itself and suicidal ideation [19]. Evidences from high-income countries indicate that maternal AAS has similar effects on children's emotional, behavioral and physical development as do maternal depression [20]. Paternal ADS is negatively associated with intimate relationship satisfaction [2], parenting practices [21], and emotional and behavioral outcome of children [22].

Risks for maternal ADS differ between high-income countries and LMIC $[8,12]$. Studies from Asian countries reported that risk factors for maternal ADS included socioeconomic disadvantage, unintended pregnancy, intimate partner violence (IPV), lack of social and family support, life stress, insufficient emotional and practical support, having hostile in-laws, sex preference for the unborn child, and history of mental illness [12, 23, 24]. A systematic review of 97 papers indicated that the risk factors for maternal AAS are analogous to the risk factors of maternal ADS [25]. However, the risk factors for paternal ADS are poorly understood. Based on the systematic review by Wee et al. [2], the most common correlate for paternal ADS were having a partner with elevated depressive symptoms and poor relationship satisfaction. Similar evidence is lacking in LMIC.

Research in Asia including Malaysia mostly reported on maternal postpartum depression, a few on maternal ADS $[10,26]$ and AAS $[10,23]$. Data on expectant fathers are not available. ADS and AAS have not yet been investigated together and simultaneously for expectant mothers and fathers in Malaysia. This study aimed to estimate the prevalence and to identify the determinants of ADS and AAS in expectant mothers and fathers. The study also compared the prevalence of ADS, AAS and co-occurring significant symptoms between expectant mothers and fathers in the east and west coasts of Malaysia.

\section{Methods \\ Study design and setting}

Data for this cross-sectional study were originated from the baseline phase (third trimester of pregnancy) of a larger prospective cohort study of parents and their infants, which aimed to assess the impact of parental perinatal depressive and anxiety symptoms on infants' growth and development. The prospective cohort study recruited expectant mothers and fathers during the third trimester of pregnancy, and followed up mothers, fathers and infants at birth, 2-3 and 6-8 months postpartum on parents' depressive and anxiety symptoms and infants' growth and development. The study was conducted in health clinics in Pahang and Selangor states in the east and west 
coasts of the peninsular Malaysia, respectively. The population in Pahang is largely rural, religious and poor, where the economic mainstay is agriculture and mining contributing $4.2 \%$ to country's gross domestic product (GDP). The majority of women in Pahang are involved in unpaid domestic work including child care. On the contrary, Selangor is one of the most developed and populous state which is predominantly urban and contemporary. The major sources economy in Selangor are manufacturing and services sectors that contributed $22.6 \%$ to GDP (27). Pregnant women in Malaysia get free antenatal and postnatal care from government health clinics and hospitals, and majority of the births occur at hospitals. Whatever they plan to give birth in a government or private hospital, they can register and attend periodic check-ups at the nearest government health clinics.

\section{Sample}

Considering a prevalence of maternal depression of $21-22 \%$ $[26,27]$, ratio between exposed and unexposed is 1:5, prevalence of child outcomes on underweight and wasting $12 \%$ and stunting $16 \%$ [28], a significance level of $5 \%$ and a power of $80 \%$, the estimated sample size for the larger prospective cohort study was 586 women (98 from exposed and 488 from unexposed). Taking into account a non-response rate of $30 \%$ and attrition rate $20 \%$, the calculated sample size at baseline was 900 expectant mothers and fathers. To attain the required sample, 10 health clinics (four from west coast and six from east coast) were selected, where the highest number of attendance for antenatal check-up was observed.

Expectant mothers and fathers who attended the health clinics for their routine antenatal care at the third trimester of pregnancy, in other words when the length of pregnancy is 7 months and onward, were invited to participate in this study. Exclusion criteria for the original cohort study included non-Malaysian, illiterate, multiple pregnancy (as it may affect the child outcome) and intrauterine death. The trained clinic nurses explained the aims and procedures of the study, and respondent's right to refuse to participate or to terminate the interview at any point. Of the 911 couples approached, 904 expectant mothers (454 from east coast and 450 from west coast) and 587 expectant fathers (440 from east coast and 147 from west coast) signed the informed consent and agreed to take part indicating participation rate of 99 and $64 \%$ in expectant mothers and fathers, respectively.

\section{Data collection}

Data for the prospective cohort study were collected during March 2016 to August 2017. Data at baseline (third trimester of pregnancy) include information on socioeconomic condition, reproductive health, perceived social support, intimate partner violence (IPV), stressful life event, previous/family history of depression, and depressive and anxiety symptoms. Data from expectant mothers were collected through self-reported structured questionnaire at the health clinics. Information from expectant fathers was collected in the same manner in a separate room, if they accompanied their wives in the clinics. Questionnaires and informed consent forms were given to expectant mothers whose husbands did not accompany them to clinics. The expectant fathers who agreed to participate signed the informed consent and filled out questionnaires, and sent them back to the respected health clinics by their wives during subsequent visits. The clinic nurses and research assistants received training on the questionnaire and data collection procedures, and scrutinized the filled in questionnaires for any missing data. The questionnaire was pretested with pregnant women in a clinic other than the study sites, and was revised based on feedback received in the field test.

\section{Assessment of explanatory variables}

Age of the respondents was calculated in years. Socioeconomic status was indicated by respondent's educational level (primary, secondary or tertiary), income earner (yes or no), occupation (government employee, non-government employee, self-employed or unemployed/homemaker), monthly household income and living condition (own house, rental house or living with parents/in-laws). Based on the monthly household income, the household was ranked as high (>RM 5599), middle (RM 2300-RM 5599) or low income $(<$ RM 2300) [29]. The obstetric indicators encompassed parity (primi or multipara), number of children, whether the current pregnancy was planned or unplanned, and preferences for gender on unborn child. Facing restriction during pregnancy was assessed if the expectant mothers were confronting any involuntary dietary restriction or movement restriction or both during pregnancy.

IPV was indicated by a lifetime experience of physical violence ever by the husband, forced sex ever, and physical violence during pregnancy. Physical violence included being slapped, shoved, punched, kicked or dragged on the ground by the partner [30]. The total score of physical violence was ranging from 0 to 4 , and categorized as no act of physical violence (0) and acts of physical violence (1-4). Respondent's perceived relationship with spouse was measured as categorical and dichotomized as good (included very good and good) and poor (included not so good and bad). Expectant fathers' support towards their wives in household chores was considered as a proxy indicator of good spousal relationship.

Perceived social support was assessed by the validated Malay version of Multidimensional Scale of Perceived Social Support (MSPSS) [31]. MSPSS included 12 items, scored on a 7-point scale from 1 (very strongly disagree) to 7 (very strongly agree). The scale was categorized as low 
support (mean score 1-2.9), moderate support (mean score 3-5) and high support (mean score 5.1-7). MSPSS comprised of three subscales, including family support (4 items), friends' support (4 items) and significant other support (4 items), a higher score indicating more support [32]. The scale demonstrated good internal consistency in the present study with the Cronbach's alpha between 0.87 and 0.94 on the three subscales.

Stressful life event was assessed by six questions, scored 1 (yes) or 0 (no): 1) any life-threatening illness, 2) any life-threatening accident, 3 ) loss of family members/ friends that affects daily living activities, 4) any event/ torture/abuse that emotionally putting down, 5) severe financial difficulty, 6) any other situation that extremely frightening or horrifying in which they felt extremely helpless. A scale was composed ranging from 0 to 6 , and dichotomized as 0 indicating experiencing no stressful life events and 1-6 experiencing stressful life events.

\section{Measurement of depressive symptoms}

The Edinburgh Postnatal Depression Scale (EPDS) was used to detect depressive symptoms among parents during pregnancy [33]. The EPDS is a 10-item self-administered questionnaire, where each item is rated on a 4-point scale $(0-3)$, with total score ranging from 0 to 30 . The scale rates the intensity of depressive symptoms in the last 7 days where higher score indicates more depressive symptoms. The items assessed dysphoric mood (five items), anxiety (two items), guilt (one item), ability to cope with everyday life (one item), and suicidal thought (one item). The reliability and validity of the Malay version of the EPDS was verified, whereby a score of 11.5 represented the optimum cut-off point for $72.7 \%$ sensitivity, $95 \%$ specificity and $80 \%$ positive predictive value [34]. Therefore, expectant mothers with an EPDS score $\geq 12$ was categorized as having depressive symptoms and $\geq 16$ as severe depressive symptoms in this study. The EPDS was also validated for use among expectant fathers, and the recommended cut-off point is $\geq 10$ for them [35]. The scale presented good reliability in the study with Cronbach's alpha of 0.75 .

\section{Measurement of anxiety symptoms}

General anxiety was assessed using the validated Malay version of the anxiety sub-scale of Depression, Anxiety and Stress Scale (DASS 21) [36]. It was used to screen and measure the level of anxiety over the previous week. DASS 21 comprised of 21 questions, which are subdivided into three domains with seven questions in each, to represent domains of depression, anxiety and stress. The choice of response ranged from 0 ('did not apply at all') to 3 ('applied very much' or 'most of the time'). In this research we used only the anxiety scale items of 2, 4, 7, 9, 15, 19 and 20. As we used the short version of DASS (21 v 42 items), score on the DASS 21 anxiety was multiplied by 2 to calculate final score of anxiety symptoms [37]. The cut-off point used in the study was $\geq 8$ to estimate the prevalence and $\geq 15$ to estimate severe anxiety symptoms [37]. The DASS 21 anxiety scale showed a good reliability in this study with Cronbach's alpha of 0.74 .

Co-occurring significant symptoms were assessed if the expectant mothers scored $\geq 12$ on EPDS and $\geq 8$ on DASS 21 anxiety scale, and expectant fathers scored $\geq 10$ on EPDS and $\geq 8$ on DASS 21 anxiety scale.

\section{Analysis}

Descriptive analyses were performed for background characteristics of the respondents and prevalence of ADS and AAS. Point prevalence of ADS and AAS during third trimester of pregnancy was calculated by dividing the number of cases by the total number of non-missing outcome data at that time. An independent t-test was used to compare means of age, family support, friends' support and significant other support of MSPSS between expectant mothers and fathers. Bivariate analyses $\left(\chi^{2}\right.$ test, Fisher's exact test and Pearson's point bi-serial correlation coefficient) were conducted between each independent variable and the outcome variables ADS and AAS independently to identify the possible contributory factors. The independent variables with $p<0.05$ were considered as possible contributory factors and included in the multiple logistic regression enter models. The outcome variables i.e. ADS and AAS were measured as both numerical and dichotomous. However, as there were well-known and recommended cut-off points on both variables, we used the outcome variables as dichotomous in multiple logistic regression. Subsequently a final model was emerged using only the significant variables ascertained in multiple regression models. We reported an odds ratio (OR) at $95 \%$ confidence level to indicate the likelihood of reporting depressive and anxiety symptoms. Any violation of assumption was observed by examining the interaction between explanatory variables in the models.

\section{Results \\ Sample profile}

The final sample included 904 expectant mothers (50.2\% from west coast and $49.8 \%$ from east coast) with a mean age of 29 years and 583 expectant fathers (24.5\% from west coast and $75.5 \%$ from east coast) with a mean age of 32 years in the third trimester of pregnancy after excluding four men because of missing outcome data. Expectant mothers were more educated than fathers in east coast, while no difference was observed in west coast. Half of the expectant mothers in east coast and one-third in west coast were homemakers. More expectant fathers were employed in private or public sector in west coast than in east coast. Nearly all the participants (>90\%) were Muslim and the majority were Malay 
(Table 1). Approximately $53 \%$ of the participants were from middle income level with median monthly household income of RM 3300 and 26\% from low income level with significantly higher proportion fitted in east coast $(36.5 \%)$ than in west coast $(16.2 \%)$. Three quarters of the respondents were living in nuclear family with husband and children, amongst 60\% lived in rented houses (data not shown).

No significant differences were observed between the expectant mothers whose spouse agreed or disagreed to participate in the study in terms of age, race, religion and parity. However, a higher percentage of expectant mothers whose spouse did not agree to participate were from west cost $\left(\chi^{2}=555.53 ; p<0.001\right)$, richer $\left(\chi^{2}=39.789 ; p<0.001\right)$, more likely to be income earner $\left(\chi^{2}=13.993 ; p<0.001\right)$ or empolyed $\left(\chi^{2}=28.891 ; p<0.001\right)$, and had a tertiary level of education $\left(\chi^{2}=26.067 ; p=0.001\right)$.

\section{Obstetric profile}

Almost $36 \%$ of the respondents were primiparas with higher proportion fitted in west coast $\left(\chi^{2}=6.778 ; p=0.009\right)$. The mean number of children was two. Six percent of the parents experienced the death of 1-2 children, including stillbirth; and $18 \%$ of the mothers experienced abortion. Three out of every 10 expectant mothers faced cultural restrictions related to food and/or movement during pregnancy with higher proportion $(p=0.001)$ in west coast (36\%) than in east coast (25.8\%) (data not shown). Half of the respondents stated that the current pregnanacy was planned. More expectant fathers than expectant mothers expressed a desire to have son in both settings (Table 1).

\section{Social support, intimate partner violence and stressful life event}

Expectant mothers received higher perceived social support than expectant fathers, with a mean score of 23.0 (SD 3.5) for expectant mothers and 21.9 (SD 3.7) for expectant fathers on MSPSS-family support, and 20.5 (SD 4.0) for expectant mothers and 19.6 (SD 3.9) for expectant fathers on MSPSS-friend's support (data not shown). However, no significant difference between expectant mothers and fathers was noted in perceived social support after stratification by sites. More than $90 \%$ of the expectant fathers support their wives in household chores. Three percent of the expectant mothers in both west and east coasts reported of being the victim of at least a single act of IPV ever, including $1.4 \% \quad(n=13)$ reporting physical abuse during the current pregnancy (Table 1). About $2 \%$ of the expectant mothers experienced of being forced to have sex with their spouse (data not shown). One-fifth of the expectant mothers and one-tenth of the expectant fathers reported that their relationship with their spouses was poor, with significantly higher proportion fitted in west coast. Conversely, more expectant fathers than expectant mothers experienced single or multiple stressful life events in their life. Overall, expectant mothers were more likely to report depression in earlier pregnancy and history of previous depressive symptoms than expectant fathers (Table 1).

\section{Prevalence of antepartum depressive and anxiety symptoms}

Of the 904 expectant mothers assessed during their third trimester of pregnancy, 110 had EPDS scores $\geq 12$ and 206 had DASS 21 anxiety scores $\geq 8$ indicating an ADS point prevalence of $12.2 \%\left(\mathrm{CI}_{95} 10.7-13.7 \%\right)$ and AAS point prevalence of $28.8 \%\left(\mathrm{CI}_{95} 25.8-31.8 \%\right)$. Similarly, the point prevalence of ADS was $8.4 \%\left(\mathrm{CI}_{95} 6.1-10.7 \%\right)$ and AAS was $13.3 \%\left(\mathrm{CI}_{95} 10.5-16.1 \%\right)$ in expectant fathers. The expectant mothers had higher rate of ADS $\left(\chi^{2}=5.26, p=.022\right)$ and AAS $\left(\chi^{2}=48.64, p<0.001\right)$ than expectant fathers. Similarly the expectant mothers had twice as high the prevalence of co-occuring significant symptoms than expectant fathers $\left(\chi^{2}=49.06, p .0<001\right)$ (Fig. 1). The point prevalence of AAS was found to be higher in west coast than in east coast in both expectant mothers $(34.0 \%$ vs. $23.6 \%, p=.001)$ and fathers $(18.4 \%$ vs. $11.6 \%, p=.037)$. However, no differences were noted between two sites in the prevalence of ADS $(13.0 \%$ in west cost vs. $11.0 \%$ in east coast, $p=.445$ in expectant mothers, and $9.8 \%$ in west coast vs. $8.0 \%$ in east coast, $p=.492$ in expectant fathers) and co-occurring significant symptoms $(8.2 \%$ in west cost vs. $7.8 \%$ in east coast, $p=.829$ in expectant mothers, and $3.5 \%$ in west coast vs. $4.1 \%$ in east coast, $p=.773$ in expectant fathers) in expectant mothers and fathers (data not shown).

Twenty-eight expectant mothers (3.1\%) and seven expectant fathers $(1.2 \%)(p=.019)$ scored $\geq 16$ on EPDS, and $39(4.3 \%)$ expectant mothers and nine expectant fathers $(1.5 \%)(p=.009)$ scored $\geq 15$ on DASS anxiety. Seven depressed expectant mothers and one depressed expectant father thought of harmimg themselves quite often (data not shown).

\section{Determinants of antepartum depressive and anxiety symptoms}

After adjusting with possible associated factors, the multiple logistic regression models showed both protective and risk factors for ADS among the expectant mothers and fathers. The protective factors included high perceived social support for expectant mothers and higher family support for expectant fathers (Tables 2 and 3). Maternal depressive symptoms were independently and positively associated with IPV ever, poor relationship with husband, depression in earlier pregnancy, and husband's depression in current pregnancy (Table 2). On the contrary, the risk of paternal depression increased with living condition (if living in a rented house), son 
Table 1 Background profile of the respondents at third trimester of pregnancy (in percent unless otherwise specified)

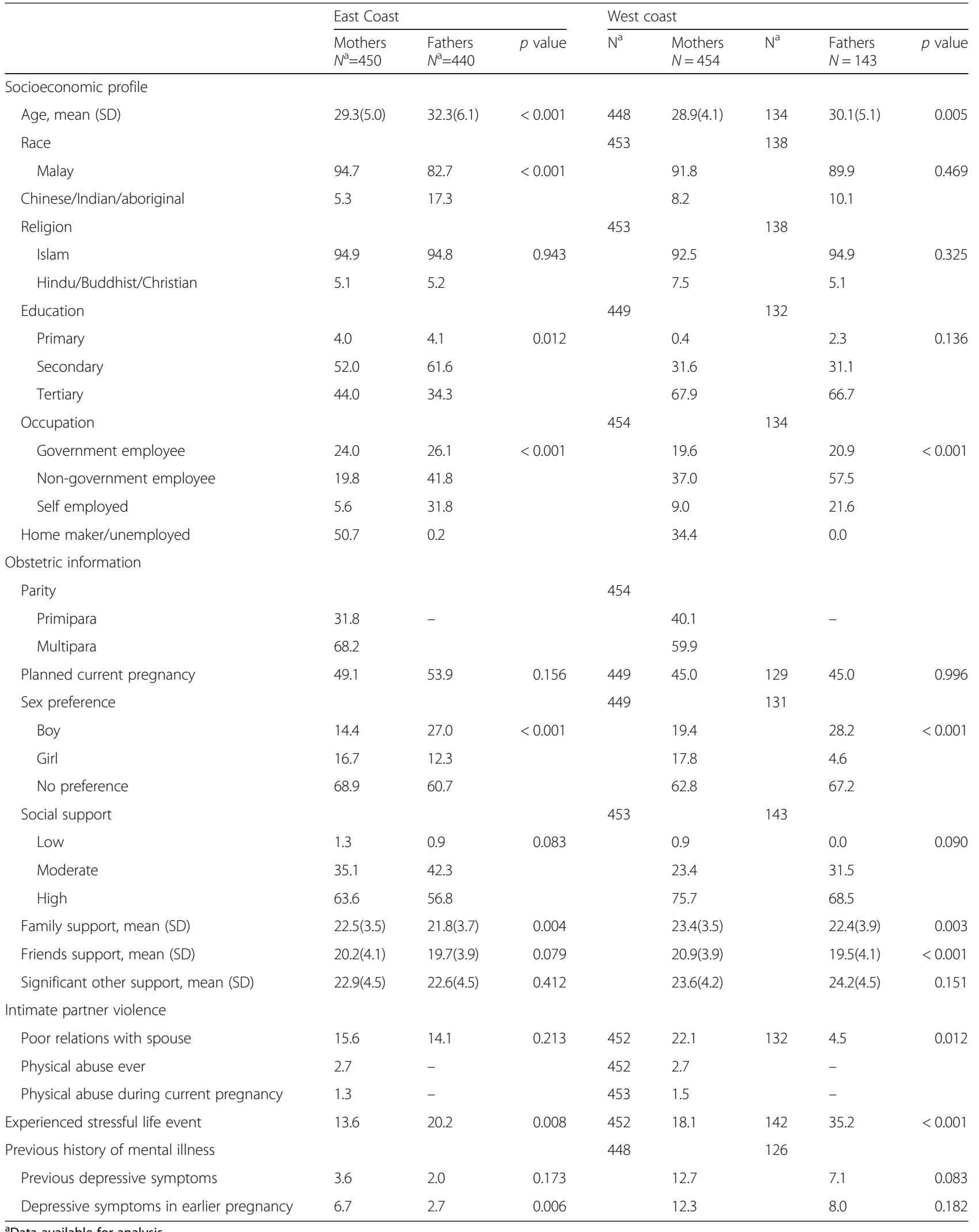

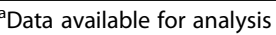




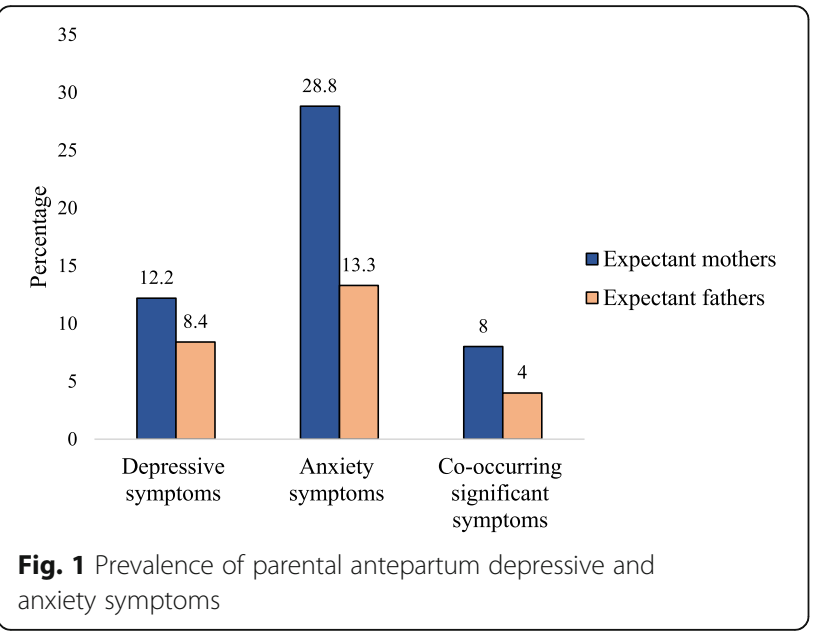

preference, stressful life event, and depression during wife's earlier pregnancy (Table 3). No significant interaction between explanatory variables was found. The Hosmer and Lemeshow tests $(p=.281$ for expectant mothers' model and $p=.748$ for expectant fathers' model) indicated that the models fit the data well. Site was not included in multiple logistic regression as it was not associated with ADS in bi-variate analysis in both expactant mothers and fathers.

The adjusted logistic regression models also identifed the determinants for AAS. The risk of AAS increased for expectant mothers with living condition (living with parents/in-laws), high family support, poor relationship with husband, restriction during preganacy, and stressful life event (Table 4). The risk of AAS for expectant fathers decreased if he supported his wife in household chores, and increased with stressful life event (Table 5). There was no association between AAS and the variation of study sites. No interaction effect of explanatory variables was observed.

\section{Discussion}

The current study is the first study that we are aware of to examine the depressive, anxiety and co-occurring significant symptoms both in expectant mothers and fathers in Malaysia. The result shows that ADS is prevalent in almost one in every eight expectant mothers and one in every 12 expectant fathers in the east and west coasts of Malaysia. Our prevalence of ADS in expectant mothers $(12.2 \%)$ is in line with the previous report from a systematic review (12\%) [6] and from Sabah (13.8\%) in Borneo island in Malaysia [26]. However, the prevalence reported in the study is lower than the prevalence from Penang $(20 \%)$ [38], but higher than the report from Ipoh $(8.6 \%)$ in the northern part of Malaysia [39]. The heterogeneity observed in the prevalence rates may be potentially related to different assessment methods, multiple cut-off scores, different assessment times, or differences between populations [40].
The prevalence of ADS in expectant fathers (8.4\%) in the current study is lower compared to expectant mothers' rate and identical with the meta-estimate of $8.4 \%$ reported in an updated meta-analysis of paternal depression in pregnancy [4]. A prevalence of ADS of $8 \%$ in expectant fathers seems rather high, nonetheless Cameron et al. [4] suggested that the prevalence of expectant father's depressive symptoms during their partners' pregnancy are nearly twice as high as the rate of depressive symptoms in the general male population. Thus, it indicates that transition to parenthood in men are at high risk of developing depression like women. Moreover, $3.1 \%$ of expectant mothers and $1.2 \%$ of expectant fathers had an episode of severe depression. These expectant mothers and fathers should be closely monitored and supported after birth, since not only the presence of ADS increases the risk of depressive symptoms after birth, also the severity of ADS matters [41].

This study reported that AAS occurred in just over 1 in 4 expectant mothers and 1 in 10 expectant fathers indicating that AAS is more common than ADS both in expectant mothers and fathers during the third trimester of pregnancy as expected from literature review [1]. A recent meta-analysis conducted in 34 countries (including Malaysia) reported a mean weighted prevalence of AAS of $24.6 \%$ in expectant mothers during the third trimester, and this prevalence is higher in LMIC than in high-income countries [42]. The current study confirms the meta-analysis results as the prevalence of AAS was high in Malaysia, and in line with the prevalence in Bangladeshi expectant mothers (29.4\%) during their third trimester of pregnancy [23].

The prevalence of co-occurring significant symptoms in expectant mothers was double (8\%) than that for expectant fathers (4\%). Consistent with Austin et al. [43], we found that two-thirds of the expectant mothers with ADS also experienced anxiety symptoms. Our prevalence is compatible with a meta-estimate of comorbid symptoms of $9.5 \%$ in expectant mothers across all trimesters from 30 different countries [44], and $10 \%$ in expectant mothers and 3\% in expectant fathers during third trimester of pregnancy from Portugal [1]. However, we found a higher rate compared with $4 \%$ in expectant mothers from Vietnam [45].

Systematic reviews assessed stressful life event and lack of social support as important risk factors for ADS and AAS $[2,8,25]$. The positive association of stressful life events was pronounced in our study on the outcome of ADS in expectant mothers and fathers, and AAS in expectant mothers not expectant fathers. Pregnancy is a well-recognized time of stress because of potential changes and challenges, and the occurrence of one or more stressful events can lead to an increase in the probability that mothers and fathers experience psychiatric 
Table 2 Logistic regression model examining associated factors of expectant mothers' depressive symptoms

\begin{tabular}{|c|c|c|c|c|}
\hline \multirow[t]{2}{*}{ Associated factors } & \multicolumn{2}{|l|}{ Full model } & \multicolumn{2}{|l|}{ Final model } \\
\hline & Adjusted OR & $\mathrm{Cl}_{95 \%}$ & Adjusted OR & $\mathrm{Cl}_{95 \%}$ \\
\hline \multicolumn{5}{|l|}{ Socioeconomic status } \\
\hline \multicolumn{5}{|l|}{ Income earner } \\
\hline No & 1 & & & \\
\hline Yes & 1.08 & $0.51-2.26$ & - & \\
\hline \multicolumn{5}{|l|}{ Economic status } \\
\hline High income & 1 & & & \\
\hline Middle income & 1.07 & $0.44-2.59$ & - & \\
\hline Low income & 1.55 & $0.53-4.49$ & - & \\
\hline \multicolumn{5}{|l|}{ Social support } \\
\hline Low support & 1 & & 1 & \\
\hline Moderate support & 0.12 & $0.02-0.65$ & 0.16 & $0.03-0.73$ \\
\hline High support & 0.09 & $0.02-0.50$ & 0.13 & $0.03-0.59$ \\
\hline \multicolumn{5}{|l|}{ Intimate partner violence } \\
\hline \multicolumn{5}{|c|}{ Experienced physical violence ever } \\
\hline No & 1 & & 1 & \\
\hline Yes & 10.93 & $2.79-42.83$ & 12.13 & $3.48-42.23$ \\
\hline \multicolumn{5}{|c|}{ Relationship with husband } \\
\hline Good & 1 & & 1 & \\
\hline Poor & 3.50 & $1.78-6.87$ & 3.92 & $2.05-7.53$ \\
\hline \multicolumn{5}{|c|}{ Pregnancy related indicators } \\
\hline \multicolumn{5}{|c|}{ Planned current pregnancy } \\
\hline No & 1 & & & \\
\hline Yes & 0.65 & $0.35-1.21$ & - & \\
\hline \multicolumn{5}{|c|}{ Husband's sex preference } \\
\hline No & 1 & & & \\
\hline Yes & 1.18 & $0.62-2.23$ & - & \\
\hline \multicolumn{5}{|c|}{ Restriction during pregnancy } \\
\hline No & 1 & & & \\
\hline Yes & 1.73 & $0.90-3.35$ & - & \\
\hline \multicolumn{5}{|l|}{ Stressful life event } \\
\hline No & 1 & & & \\
\hline Yes & 1.86 & $0.89-3.88$ & - & \\
\hline \multicolumn{5}{|l|}{ History of mental illness } \\
\hline \multicolumn{5}{|c|}{ Previous history of depression } \\
\hline No & 1 & & & \\
\hline Yes & 0.96 & $0.31-2.98$ & - & \\
\hline \multicolumn{5}{|c|}{ Depression in earlier pregnancy } \\
\hline No & 1 & & 1 & \\
\hline Yes & 5.48 & $2.35-12.79$ & 6.78 & $3.21-14.34$ \\
\hline \multicolumn{5}{|c|}{ Husband's depression in current pregnancy } \\
\hline No & 1 & & 1 & \\
\hline Yes & 2.68 & $1.16-6.17$ & 3.95 & $1.79-8.70$ \\
\hline
\end{tabular}


Table 3 Logistic regression showing factors associated with expectant fathers' depressive symptoms

\begin{tabular}{|c|c|c|c|c|}
\hline \multirow[t]{2}{*}{ Associated factors } & \multicolumn{2}{|l|}{ Full model } & \multicolumn{2}{|l|}{ Final model } \\
\hline & Adjusted OR & $\mathrm{Cl}_{95 \%}$ & Adjusted OR & $\mathrm{Cl}_{95 \%}$ \\
\hline \multicolumn{5}{|l|}{ Socioeconomic status } \\
\hline \multicolumn{5}{|l|}{ Living condition } \\
\hline Own house & 1 & & 1 & \\
\hline Rented house & 2.67 & $1.11-6.45$ & 2.53 & $1.08-5.92$ \\
\hline Living with parents/others & 0.70 & $0.20-2.48$ & 0.77 & $0.23-2.59$ \\
\hline \multicolumn{5}{|l|}{ Social support } \\
\hline Family support & 0.82 & $0.72-0.94$ & 0.83 & $0.76-0.90$ \\
\hline Friends support & 1.03 & $0.91-1.16$ & - & \\
\hline Significant other support & 1.04 & $0.95-1.13$ & - & \\
\hline \multicolumn{5}{|l|}{ Partner relationship } \\
\hline \multicolumn{5}{|l|}{ Relationship with wife } \\
\hline Good & 1 & & & \\
\hline Poor & 1.91 & $0.72-5.06$ & - & \\
\hline \multicolumn{5}{|l|}{ Help wife in household chores } \\
\hline No & 1 & & & \\
\hline Yes & 0.51 & $0.17-1.57$ & - & \\
\hline \multicolumn{5}{|l|}{ Pregnancy related indicator } \\
\hline \multicolumn{5}{|l|}{ Son preference } \\
\hline No & 1 & & 1 & \\
\hline Yes & 2.35 & $1.13-4.86$ & 2.32 & $1.15-4.67$ \\
\hline \multicolumn{5}{|l|}{ Stressful life event } \\
\hline No & 1 & & 1 & \\
\hline Yes & 2.62 & $1.25-5.47$ & 2.92 & $1.45-5.85$ \\
\hline \multicolumn{5}{|l|}{ History of mental illness } \\
\hline \multicolumn{5}{|c|}{ Depression in wife's earlier pregnancy } \\
\hline No & 1 & & 1 & \\
\hline Yes & 21.26 & $6.34-71.32$ & 19.69 & $6.66-58.23$ \\
\hline \multicolumn{5}{|c|}{ Wife's depression in current pregnancy } \\
\hline No & 1 & & & \\
\hline Yes & 2.40 & $0.96-5.97$ & - & \\
\hline
\end{tabular}

morbidities [25]. However, the study highlighted the importance of perceived social/family support in protecting expectant mothers and fathers from ADS and adds to the prior studies from Malaysia during ante [38] and postpartum period [29]. Several studies indicate social/family support during pregnancy and childbirth may be of special significance in the context of traditional Asian society, including in Malaysia [29, 46]. Adequate support may act as a buffer against the harmful effect of other stressors and difficulties experienced in the transition to parenthood, protecting parental mental health [25]. Surprisingly, this study shows that expectant mothers living in extended families together with parents or in-laws with high family support were more likely to experience AAS, compared to expectant mothers cohabiting with their partners in their own houses. Similar association with depressive symptoms was reported from Italy [47] and Malaysia [29]. Azidah et al. [29] clarified that mothers who had good social support involved in traditional practices related to birth, were more likely to show depressive symptoms compared to mothers who did not follow traditional practices [29]. These findings contradicted the view that traditional practices with family support related to birth is protective against depressive symptoms [46]. Rashid and Mohd [38] explained that in a contemporary society mothers might feel pressure to carry out traditional activities in which they no longer believed in.

Despite a low prevalence of IPV ever (2.6\%) and physical abuse during the current pregnancy $(1.3 \%)$, IPV was 
Table 4 Logistic regression model showing determinants of expectant mothers' anxiety symptoms

\begin{tabular}{|c|c|c|c|c|}
\hline \multirow[t]{2}{*}{ Associated factors } & \multicolumn{2}{|l|}{ Full model } & \multicolumn{2}{|l|}{ Final model } \\
\hline & Adjusted OR & $\mathrm{Cl}_{95 \%}$ & Adjusted OR & $\mathrm{Cl}_{95 \%}$ \\
\hline \multicolumn{5}{|l|}{ Socioeconomic status } \\
\hline \multicolumn{5}{|l|}{ Site } \\
\hline East coast & 1 & & & \\
\hline West coast & 1.22 & $0.87-1.71$ & - & \\
\hline \multicolumn{5}{|l|}{ Education } \\
\hline Primary & 1 & & & \\
\hline Secondary & 2.42 & $0.53-11.08$ & - & \\
\hline Tertiary & 3.53 & $0.76-16.37$ & - & \\
\hline \multicolumn{5}{|l|}{ Income earner } \\
\hline No & 1 & & 1 & \\
\hline Yes & 0.60 & $0.42-0.84$ & 0.73 & $0.53-1.00$ \\
\hline \multicolumn{5}{|l|}{ Living condition } \\
\hline Own house & 1 & & 1 & \\
\hline Rented house & 1.29 & $0.87-1.91$ & 1.47 & $1.01-2.13$ \\
\hline Living with parents/in-laws & 1.82 & $1.15-2.88$ & 2.18 & $1.41-3.37$ \\
\hline \multicolumn{5}{|l|}{ Social support } \\
\hline Family support & 1.05 & $1.01-1.13$ & 1.07 & $1.03-1.13$ \\
\hline \multicolumn{5}{|l|}{ Intimate partner violence } \\
\hline \multicolumn{5}{|c|}{ Physical violence during pregnancy } \\
\hline No & 1 & & & \\
\hline Yes & 3.87 & $0.94-15.90$ & - & \\
\hline \multicolumn{5}{|l|}{ Relationship with husband } \\
\hline Good & 1 & & 1 & \\
\hline Poor & 1.49 & $0.98-2.27$ & 1.74 & $1.17-2.57$ \\
\hline \multicolumn{5}{|l|}{ Pregnancy related indicators } \\
\hline \multicolumn{5}{|l|}{ Parity } \\
\hline Multi & 1 & & & \\
\hline Primi & 1.08 & $0.66-1.70$ & - & \\
\hline Number of children & 0.88 & $0.74-1.06$ & - & \\
\hline \multicolumn{5}{|l|}{ Husband's sex preference } \\
\hline No & 1 & & & \\
\hline Yes & 1.09 & $0.78-1.53$ & - & \\
\hline \multicolumn{5}{|l|}{ Restriction during pregnancy } \\
\hline No & 1 & & 1 & \\
\hline Yes & 2.22 & $1.59-3.11$ & 2.30 & $1.63-3.13$ \\
\hline \multicolumn{5}{|l|}{ Stressful life event } \\
\hline No & 1 & & 1 & \\
\hline Yes & 1.77 & $1.16-2.68$ & 1.84 & $1.23-2.75$ \\
\hline
\end{tabular}

found to be one of the strongest predictors of ADS in the current study. There are robust evidences of the adverse impact of IPV on women's mental health [9], and on depression in particular during the perinatal period [48], when a mother is more dependent. IPV during pregnancy has serious consequences for both the mother and her unborn baby, such as miscarriage, risk of low birth-weight, pre-term labor, and fetal death [48]. Consistent with other research $[2,49]$, this study shows that poor relationship with husband is another strong predictor of 
Table $\mathbf{5}$ Logistic regression examining determinants of expectant fathers' anxiety symptoms

\begin{tabular}{|c|c|c|c|c|}
\hline \multirow[t]{2}{*}{ Associated factors } & \multicolumn{2}{|l|}{ Full model } & \multicolumn{2}{|l|}{ Final model } \\
\hline & Adjusted OR & $\mathrm{Cl}_{95 \%}$ & Adjusted OR & $\mathrm{Cl}_{95 \%}$ \\
\hline \multicolumn{5}{|l|}{ Demographic indicator } \\
\hline \multicolumn{5}{|l|}{ Site } \\
\hline East coast & 1 & & & \\
\hline West coast & 1.38 & $0.79-2.43$ & - & \\
\hline \multicolumn{5}{|l|}{ Social support } \\
\hline Friends support & 0.94 & $0.88-1.00$ & - & \\
\hline \multicolumn{5}{|l|}{ Spousal relations } \\
\hline \multicolumn{5}{|c|}{ Help wife in household chores } \\
\hline No & 1 & & 1 & \\
\hline Yes & 0.37 & $0.17-0.83$ & 0.40 & $0.18-0.87$ \\
\hline \multicolumn{5}{|c|}{ Pregnancy related indicator } \\
\hline Number of children & 0.88 & $0.72-1.07$ & - & \\
\hline \multicolumn{5}{|l|}{ Stressful life event } \\
\hline No & 1 & & 1 & \\
\hline Yes & 2.62 & $1.56-4.39$ & 2.82 & $1.70-4.70$ \\
\hline
\end{tabular}

ADS in expectant mothers. Although $19 \%$ of the study expectant mothers acknowledged poor relationship with their husbands, its impact on women's mental health is clearly noticeable in their increased likelihood of reporting depressive symptoms. Risk is also increased among the expectant fathers with the expected sex of the unborn child. The gender preference in favour of a boy has been deeply ingrained in some Asian societies [12], possibly more in expectant fathers than in expectant mothers. Although the participants were not aware about the sex of the unborn child, surprisingly more than one-quarter of expectant fathers in both sites preferred for a boy child. Gender preference and the manifestations of sex preferential behavior are expected to be intrinsically influenced by family, community, and sociocultural norms and expectations, and should not be considered solely the result of parental desires [12].

Previous depression at any time during lifetime and depression during previous pregnancies have been recognised as potential predictors for $\operatorname{ADS}[2,8,25]$. In our study, we found only depression in earlier pregnancy both among expectant mothers and fathers, husband's depression in current pregnancy in expectant mothers, but not previous depression in life predicted ADS at third trimester of pregnancy. The association between ADS in expectant mothers and having a depressed husband has been confirmed by Nath et al. [40], which indicates that the family may be more vulnerable if men, who often is the breadwinner in the family becomes ill. There are growing evidences that depression either in expectant mothers or in expectant fathers, increases the likelihood for both to develop ADS $[2,5]$.
Studies that have examined the association between socioeconomic status and depressive and anxiety symptoms have reported contradictory results [2, 5, 8, 9]. Contrasting findings reported by Wee et al. [2] and Paulson and Bazemore [5] that no association between ADS/ AAS and socioeconomic factors was observed either in expectant mothers or in expectant fathers in the current study. However, consistent with a systematic review by Biaggi et al. [25], our study indicates that expectant mothers are protected against AAS if they are income earner, and expectant fathers are more likely to experience ADS if they live in rented houses. Nath et al. [40] explained that the economy may not be directly associated with ADS/AAS, but it may moderate the relationship between other risk factors and ADS/AAS in expectant mothers and fathers. Contrary to prior research [50], this study did not find any association between ADS/AAS and deviances associated with urbanization. This may be because the sampling was not implemented with independent sample to compare between two study sites.

Several methodological limitations should be considered when interpreting the findings. EPDS is known to have a high rate of false positive as the detection of depression can be impeded by respondent's culture, gender, and/or predominance of somatic symptoms. However, the positive predictive value at the recommended cut-off point was $80 \%$ in the validation study in Malaysia [34], indicating that $80 \%$ of the cases might be correctly diagnosed. The DASS anxiety scale has been administered in isolation, which may affect the psychometrics of the scale. Instruments used to measure IPV and stressful life event were not validated. However, translation and back 
translation of the items of those instruments were done by two bilingual social science researchers. Previous depressive symptoms were identified subjectively by asking question if the respondents were encountered similar depressive symptoms ever in lifetime and in earlier pregnancies, may introduce bias through over-estimation. In the case of reporting physical violence, expectant mothers may not have reported the actual scenario due to its sensitive nature. Several other important variables were not controlled for, such as physical illness, gynaecological morbidities, previous infertility, complications during pregnancy, other mental disorders and smoking. Because of self-reported nature of the interviews, the study recruited only the literate participants that may create a selection bias against those with low education or who have literacy difficulties. Moreover, for highly urban areas, such as Selangor state, there is a greater concern about nonresponse bias, since response rates are lower among expectant fathers; they are not only harder to contact but also less likely to cooperate even after contact. As the study was carried out in purposively selected health clinics in two states of east and west coasts of Malaysia, the findings cannot be generalised.

\section{Conclusion}

Our study confirms that ADS, AAS and co-occurring significant symptoms during the third trimester of pregnancy are common in both expectant mothers and fathers, and that stressful life events, IPV, poor relationship with husband, lack of perceived social/family support, depression in earlier pregnancy, and sex preference for unborn child (expectant fathers only) are independent factors associated with ADS and AAS. The main implication of the results is to integrate a couple-focused screening intervention into the antenatal care services to prevent ADS, AAS and co-occurring significant symptoms. Because of the high costs associated with clinical interviews, research suggested to use screening instruments to identify psychiatric morbidities in LMIC. All pregnant women and their accompanying husbands attending the health clinics for antenatal check-up should be screened for ADS and AAS by the clinic nurses using the locally validated EPDS and DASS-Anxiety. The more structured clinical interview can be followed only for those who screen positive, both expectant mothers and fathers. Moreover, the policies aimed at referring couples with depressive and anxiety symptoms to the nearest health care facilities where psychological treatment is available may help couples in receiving appropriate support.

\section{Abbreviations}

AAS: Antepartum anxiety symptoms; ADS: Antepartum depressive symptoms; DASS: Depression, anxiety and stress scale; EPDS: Edinburgh postnatal depressive scale; IPV: Intimate partner violence; LMIC: Low- and middleincome countries; MSPSS: Multidimensional scale of perceived social support

\section{Acknowledgments}

The authors thank all clinic nurses and staff involved in helping the data collection. The authors also express gratitude to the women and men who participated in the study for generously giving their time and energy and providing personal details to the interviews. We would like to thank the Director General of Health, Malaysia for his permission to publish this article.

\section{Funding}

The study was supported by grants from the Ministry of Higher Education, Malaysia under the Fundamental Research Grant Scheme (FRGS15-238-0479).

\section{Availability of data and materials}

The dataset generated and analyzed during the current study are not publicly available due to confidentiality issues but are available from the corresponding author on reasonable request.

\section{Authors' contributions}

All authors (HEN, JAR, RMR, MK, RS, ME) participated in the planning and conception of the research questions and the study design. HEN was the principal investigator of the study and primarily conceptualized the research. RMR, RS and MK were responsible for retrieving the data, and HEN and JAR were responsible for analyzing the data. HEN and ME participated in interpreting the data and drafted the article. All authors critically revised the manuscript for important intellectual content. All authors read and approved the manuscript.

\section{Authors' information}

Hashima E Nasreen, MBBS, MPH, PhD, Assistant Professor of Epidemiology;

Department of Community Medicine, Faculty of Medicine, International Islamic University Malaysia, Kuantan Campus, Pahang, Malaysia.

Jamalludin Ab Rahman, MBBS, MPH, Professor of Biostatistics, Department of Community Medicine, Faculty of Medicine, International Islamic University Malaysia, Kuantan Campus, Pahang, Malaysia.

Razman Mohd Rus, MBBS, Masters in Community Medicine (Occupational Health), Associate Professor, Department of Community Medicine, Faculty of Medicine, International Islamic University Malaysia, Kuantan Campus, Pahang, Malaysia.

Mira Kartiwi, PhD, Associate Professor, Department of Information Systems, Faculty of Information and Communication Technology, International Islamic University Malaysia, Kuala Lumpur, Malaysia.

Rosnah Sutan, MBBS, PhD, Associate Professor, Public Health Specialist (Family Health Group), Community Health Department, Universiti Kebangsaan Malaysia Medical Centre, Kuala Lumpur, Malaysia. Maigun Edhborg, PhD, Senior Lecturer, Department of Neurobiology, Care Science and Society, Division of Nursing, Karolinska Institutet, Stockholm, Sweden.

\section{Ethics approval and consent to participate}

The study was approved by the Malaysia Medical Research and Ethics Committee (NMRR-15-1902-28,439) and the Research Ethics Committee (IREC 555) of International Islamic University Malaysia. The data was collected after obtaining the written informed consent. If a woman scored $\geq 16$ on the EPDS during the study, we referred her to the psychiatric department of a nearby hospital.

\section{Consent for publication}

Not applicable.

\section{Competing interests}

The authors declare that they have no competing interests.

\section{Publisher's Note}

Springer Nature remains neutral with regard to jurisdictional claims in published maps and institutional affiliations.

\section{Author details}

${ }^{1}$ Faculty of Medicine, International Islamic University Malaysia, Jalan Sultan Ahmad Shah, 25200 Kuantan, Pahang, Malaysia. ${ }^{2}$ Faculty of Information and Communication Technology, International Islamic University Malaysia, Jalan Gombak, 53100 Kuala Lumpur, Malaysia. ${ }^{3}$ Community Health Department, Universiti Kebangsaan Malaysia, Bandar Tun Razak Cheras, 56000 Kuala 
Lumpur, Malaysia. ${ }^{4}$ Department of Neurobiology, Care Sciences and Society, Karolinska Institute, SE-141 83 Huddinge, Stockholm, Sweden.

\section{Received: 29 January 2018 Accepted: 7 June 2018 Published online: 15 June 2018}

\section{References}

1. Figueiredo B, Conde A. Anxiety and depression in women and men from early pregnanacy to 3-months postpartum. Arch Womens Ment Health. 2011;14:247-55

2. Wee KY, Skouteris H, Pier C, Richardson B, Milgrom J. Correlates of ante- and postnatal depression in fathers: a systematic review. J Affect Disord. 2011; 130:358-77.

3. Lee AM, Lam SK, Sze Mun Lau SM, Chong CS, Chui HW, Fong DY Prevalence, course, and risk factors for antenatal anxiety and depression. Obstet Gynecol. 2007;110:1102-12.

4. Cameron EE, Sedov ID, Tomfohr-Madsen LM. Prevalence of paternal depression in pregnancy and the postpartum: an updated meta-analysis. J Affect Disord. 2016;206:189-203.

5. Paulson JF, Bazemore SD. Prenatal and postnatal depression in fathers and its association with maternal depression: a metal analysis. JAMA. 2010;303:1961-9.

6. Bennett HA, Einarson A, Taddio A, Koren G, Einarson TR. Prevalence of depression during pregnancy: systematic review. Obstet Gynecol. 2004;103:698-709.

7. Roomruangwong C, Epperson CN. Perinatal depression in Asian women: prevalence, associated factors and cultural aspects. Asian Biomed. 2011;5:179-93.

8. Lancaster CA, Gold KJ, Flynn HA, Yoo H, Marcus SM, Davis MM. Risk factors for depressive symptoms during pregnancy: a systematic review. Am J Obstet Gynecol. 2010;202:5-14.

9. Fisher J, Cabral de Mello M, Patel V, Rahman A, Tran T, Holton S, et al. Prevalence and determinants of common perinatal mental disorders in women in low- and lower-middle-income countries: a systematic review. Bull World Health Organ. 2012;90:139-49G.

10. Karmaliani R, Asad N, Bann C, Moss N, Mcclure EM, Pasha O, et al. Prevalence of anxiety, depression and associated factors among pregnant women of Hyderabad, Pakistan. Int J Soc Psychiatry. 2009:55:414-24.

11. Bergman K, Sarkar P, Glover V, O'Connor TG. Maternal prenatal cortisol and infant cognitive development: moderation by infant-mother attachment. Biol Psychiatry. 2010;67:1026-32.

12. Klainin P, Arthur DG. Postpartum depression in Asian cultures: a literature review. Int J Nurs Stud. 2009;46:1355-73.

13. Nasreen HE, Kabir ZN, Forsell Y, Edhborg M. Low birth weight in offspring of women with depressive and anxiety symptoms during pregnancy: results from a population based study in Bangladesh. BMC Public Health. 2010;10:515.

14. Lui C, Cnattingius S, Bergström M, Östberg V, Hjern A. Prenatal parental depression and preterm birth: a national cohort study. BJOG. 2016;123:1973-82

15. Rahman A, lqbal Z, Bunn J, Lovel H, Hurrington R. Impact of maternal depression on infant nutritional status and illness: a cohort study. Arch Gen Psychiatry. 2004;61:946-52.

16. Glover V. Maternal depression, anxiety and stress during pregnancy and child outcome: what needs to be done. Best Pract Res Clin Obstet Gynaecol. 2014;28:25-35.

17. Tronick E, Reck C. Infants of depressed mothers. Harv Rev Psychiatry. 2009; 17:147-56.

18. Harrison PA, Sidebottom AC. Alcohol and drug use before and during pregnancy: an examination of use patterns and predictors of cessation. Matern Child Health J. 2009:13:386-94.

19. Freitas GV, Cais CF, Stefanello S, Botega NJ. Psychological conditions and suicidal behavior in pregnant teenagers: a case-control study in Brazil. Eur Child Adolesc Psychiatry. 2008;17:336-42.

20. Glasheen C, Richardson GA, Fabio A. A systematic review of the effects of postnatal maternal anxiety on children. Arch Womens Ment Health. 2010;13:61-74.

21. Wilson S, Durbin CE. Effects of paternal depression on father's parenting behaviors: a meta-analytic review. Clin Psychol Rev. 2010:30:167-80.

22. Ramchandani PG, O'Connor TG, Evans J, Heron J, Murray L, Stein A. The effect of pre- and postnatal depression in fathers: a natural experiment comparing the effects of exposure to depression on offspring. J Child Psychol Psychiatry. 2008:49:1069-78.

23. Nasreen HE, Kabir ZN, Forsell Y, Edhborg M. Prevalence and associated factors of depressive and anxiety symptoms during pregnancy: a population based study in rural Bangladesh. BMC Womens Health. 2011;11:22.
24. Shidhaye R, Patel V. Association of socioeconomic, gender, and health factors with common mental disorders in women: a population-based study of 5703 married rural women in India. Int J Epidemiol. 2010;39:1510-21.

25. Biaggi A, Conroy S, Pawlby S, Pariante CM. Identifying the women at risk of antenatal anxiety and depression: a systematic review. J Affect Disord. 2016; 191:62-77.

26. Yusuff ASM, Tang L, Binns CW, Lee AH. Prevalence of antenatal depressive symptoms among women in Sabah, Malaysia. J Matern Fetal Neonatal Med. 2016;29:1170-4.

27. Azidah AK, Shaiful BI, Rusli N, Jamil MY. Postnatal depression and sociocultural practices among postnatal mothers in Kota Bahru, Kelantan, Malaysia. Med J Malaysia. 2006;61:76-83.

28. UNICEF for every child: Malaysia. UNICEF. 2013. http://www.unicef.org/ infobycountry/malaysia_statistics.html. Accessed 12 May 2015

29. Government of Malaysia. Tenth Malaysia Plan 2011-2015. Putrajaya: The Economic Planning Unit, Prime Minister's Department; 2010.

30. Garcia-Moreno C, Jansen HAFM, Ellsberg M, Heise L, Watts CH. Prevalence of intimate partner violence: findings from the WHO multi-country study on women's health and domestic violence. Lancet. 2006;368:1260-9.

31. Ng CG, Nurasikin MS, Loh HS, Anne Yee HA, Zainal NZ. Factorial validation of the Malay version of multidimensional scale of perceived social support among a group of psychiatric patients. Malaysian J Psychiatry. 2012;21:2.

32. Zimet GD, Dahlem NW, Zimet SG, Farley GK. The multidimesional scale of perceived social support. J Pers Assess. 1988:52:30-41.

33. Cox JL, Holden JM, Sagovsky R. Detection of postnatal depression: development of the 10-item Edinburgh postnatal depression scale. $\mathrm{Br}$ J Psychiatry. 1987;150:782-6

34. Azidah AK, Nordin R, Ismail SB, Yaacob MJ, Mustapha WMRW. Validation of the Malay version of Edinburgh postnatal depression scale. Asia Pac J Fam Med. 2004;3:9-18

35. Matthey S, Barnett B, Kavanagh DJ, Howie P. Validation of the Edinburgh postnatal depression scale for men, and comparison of item endorsement with their partners. J Affect Disord. 2001:64:175-84.

36. Ramli M, Mohd AF, Zaini Z. Translation, validation and psychometric properties of Bahasa Malaysia version of the depression, anxiety and stress scale (DASS). Asian J Psychiatry. 2007:8:82-9.

37. Lovibond SH, Lovibond PF. Manual for the depression, anxiety and stress scales. 2nd ed. Sydney: Psychology Foundation; 1995.

38. Rashid A, Mohd R. Poor social support as a risk factor for antenatal depressive symptoms among women attending public antennal clinics in Penang, Malaysia. BMC Reprod Health. 2017;14:144

39. Fadzil A, Balakrishnan K, Razali R, Sidi H, Malapan T, Japaraj RP, et al. Risk factors for depression and anxiety among pregnant women in hospital Tuanku, Bainum, Ipoh Malaysia. Asia Pac Psychiatry. 2013;5(Supp 1):7-13.

40. Nath S, Psychogiou L, Kuyken W, Ford T, Ryan E, Russel G. The prevalence of depressive symptoms among fathers and associated risk factors during the first seven years of their child's life: findings from the millennium cohort study. BMC Public Health. 2016:16:509-22.

41. Underwood L, Waldie KE, D'Souza S, Peterson E, Morton SMB. A longitudinal study of pre-pregnancy and pregnancy risk factors associated with antenatal and postnatal symptoms of depression: Evidence from growing up in New Zealand. Matern Child Health J. 2017:21:915-31.

42. Dennis C-L, Falah-Hassani K, Shiri R. Prevalence of antenatal and postnatal anxiety: systematic review and meta-analysis. Br J Psychiatry. 2017;210:315-23.

43. Austin MP, Hadzi-Pavlovic D, Priest SR, Reilly N, Wilhelm K, Saint K, et al. Depressive and anxiety disorders in the postpartum period: how prevalent are they and can we improve their detection? Arch Womens Ment Health 2010;13:395-401.

44. Falah-Hassani $\mathrm{K}$, Shiri $\mathrm{R}$, Dennis $\mathrm{CL}$. The prevalence of antenatal and postnatal co-morbid anxiety and depression: a meta-analysis. Psychol Med. 2017:47:2041-53.

45. Fisher J, Tran T, La BT, Kriitmaa K, Rosenthal D, Tran T. Common perinatal mental disorders in northern Viet Nam: community prevalence and health care use. Bull World Health Organ. 2010;88:737-45.

46. Lee DTS, Chan SSM, Sahota DS, Yip ASK, Tsui M, Chung TKA. A prevalence study of antenatal depression among Chinese women. J Affect Disord. 2004;82:93-9.

47. Balestrieri M, Isola M, Bisoffi G, Calo S, Conforti A, Driul L, et al. Determinants of antepartum depression: a multicenter study. Soc Psychiatry Psychiatr Epidemiol. 2012;47:1959-65. 
48. Beydoun HA, Beydoun MA, Kaufman JS, Lo B, Zonderman AB. Intimate partner violence against adult women and its associations with major depressive disorders, depressive symptoms and postpartum depression: a systematic review and meta-analysis. Soc Sci Med. 2012;75:959-75.

49. Clavarino A, Hayatbuktsh MR, William GM, Bor W, O'Collaghan M, Nijran JM. Depression following marital problems: different impact of mothers and their children? A 21-year prospective study. Soc Psychiatry Psychiatr Epidemiol. 2011;46:833-41.

50. Srivastava K. Urbanization and mental health. Ind Psychiatry J. 2009;18:75-6.

Ready to submit your research? Choose BMC and benefit from:

- fast, convenient online submission

- thorough peer review by experienced researchers in your field

- rapid publication on acceptance

- support for research data, including large and complex data types

- gold Open Access which fosters wider collaboration and increased citations

- maximum visibility for your research: over $100 \mathrm{M}$ website views per year 